\title{
Letter identification in word, nonword, and single-letter displays*
}

\author{
JAMES F. JUOLA $\dagger$, DAVID D. LEAVITT, and CHONG S. CHOE \\ University of Kansas, Lawrence, Kansas 66045
}

\begin{abstract}
Letter identification in four-letter words, four-letter nonwords, and single-letter displays was tested using a two-alternative, forced-choice procedure. The nonwords were constructed to be pronounceable and orthographically regular. All displays were tachistoscopically presented without pre- or postexposure masking fields. The mean proportions of correct choices were .749 for letters, .735 for words, and .671 for nonwords, with the latter proportion being significantly smaller than those for the other conditions. The relatively high performance for letters was attributed to the absence of masking fields in the present study, since masks have been shown to interfere more with letter processing than word processing in similar studies. The superiority of words over regular nonwords was used as evidence to support the hypothesis that the perceptual unit in reading can be at least as large as a four-letter word.
\end{abstract}

Reicher (1969) studied perceptual recognition of tachistoscopically presented letters, words, and nonword letter strings. He found that Ss were more accurate in reporting which of a given pair of letter alternatives was included in the display when words rather than nonwords or single letters were presented. Providing the letter alternatives before and after the display or only afterward had no effect on the pattern of results, although overall performance was actually better without prior information.

Subsequent studies using similar procedures have replicated the superiority of words over single letters in forced-choice letter recognition tasks (Thompson \& Massaro, 1973, Experiment I; Wheeler, 1970). However, there are conditions under which letters presented alone are apparently processed more efficiently than letters contained in words. If Reicher's (1969) procedure is altered such that only a small set of letter alternatives is used repeatedly over a series of trials, performance has generally been better for single-letter displays than for words (Bjork \& Estes, 1973; Estes, Bjork, \& Skaar, 1974; Massaro, 1973; Thompson \& Massaro, 1973, Experiment II). This apparent contradiction might have been due to the use of different processing strategies in recognition and detection tasks. If $S$ is to detect the presence or absence of one or more target letters in a brief foveal display, continued practice with these items could lead to decisions made at a relatively low level of processing. That is, features abstracted from the display could be compared directly with target feature lists held

\footnotetext{
*This research was supported in part by funds from Biomedical Sciences Support Grant RR-07037 from the National Institutes of Health, University of Kansas General Research Grant 3294-5038, and Grant MH 24637-01 from the National Institute of Mental Health to the first author. This investigation was initiated while the second author was supported by a National Science Foundation Undergraduate Research Participation program grant awarded to the Department of Psychology of the University of Kansas for the summer of 1973.

The authors thank Glen Taylor for his assistance.

†R eprint requests should be addressed to James F. Juola, Department of Psychology, University of Kansas, Lawrence, Kansas 66045
}

in memory, and a best-matching target could be selected before enough information had been processed to identify the stimulus. Performance decrements with increasing number of display characters could then be due to lateral inhibition among the letters or to the limited capacity of the comparison process. On the other hand, recognition tasks using a variable set of alternatives, which might not be known until some time after the display has terminated, could induce Ss to attempt to identify the stimulus before considering the alternatives. A word advantage in these tasks indicates that linguistic redundancy present in words facilitates the identification of their component letters and enables words to be recognized at lower thresholds than single letters (Smith, 1971).

A similar analysis of processing differences in recognition and detection tasks for words and nonword letter strings leads to the prediction that performance should be better for words in the former task, and no differences should be obtained using the detection paradigm. Empirical evidence supports this view in that Smith and Haviland (1972) replicated Reicher's (1969) word advantage over nonwords in a similar perceptual recognition task, whereas studies employing the detection paradigm have found no word-nonword differences (Bjork \& Estes, 1973; Estes, Bjork, \& Skaar, 1974; Massaro, 1973).

Words differ from nonwords in at least two major ways that could affect their relative perceptibility in recognition tasks. First, words are pronounceable and orthographically regular. These constraints are sources of information that are not necessarily present in nonwords. Second, words correspond to meaningful units in the subjective lexicon and as such could be available for matching featural information derived from the stimulus. Nonwords have no internal representation, and thus their perceptual units are limited to letters or letter clusters such as spelling patterns (e.g., Gibson, Shurcliff, \& Yonas, 1970) or vocalic center groups 
(Smith \& Spoehr, 1974). Baron and Thurston (1973) have argued that the first difference is the important one for the word superiority effect. They used a recognition task with the alternatives presented after the display and found no advantage for words over pronounceable and orthographically regular nonwords. These results are consistent with the hypothesis that the perceptual units relevant for word recognition might be larger than letters but smaller than whole words. This issue cannot yet be regarded as resolved, however, since Manelis (1974) has demonstrated a slight but significant advantage for words over pronounceable nonwords in several studies using larger stimulus samples than the Baron and Thurston study.

The present study included word, nonword, and letter displays with two letter alternatives presented on each trial, as in Reicher's (1969) experiment. Several methodological changes from earlier studies were made to provide more stringent tests of possible word superiority effects as well as to increase the relevance of this task to processes involved in reading. These included (1) the use of a large number of frequent four-letter words and an equal number of orthographically regular, pronounceable nonwords. Besides increasing the generality of the results, the large number of stimuli enabled us to use well practiced Ss without also having to repeat test items. (2) All stimuli were printed in black ink on white cards in normal, lowercase typeface. It is possible that the use of uppercase letters in other studies might have minimized differences between words and nonwords by eliminating visual information, such as the overall shape of the stimulus, that could aid in word recognition. (3) All stimuli were briefly presented without interfering noise items or masking fields.

\section{METHOD}

The Ss were eight undergraduate volunteers. The test stimuli consisted of 256 different four-letter one-syllable words, 256 different four-letter one-syllable nonwords, and 14 single letters that were also used as the response alternatives. The word frequencies varied from 1 to 10,595 per million, with a median value of 58.5 per million (Kucera \& Francis, 1967). The letters were arbitrarily divided into two groups on the basis of apparent visual similarity. Letter Group I included the letters, b, d, f, h, k, 1 and Letter Group II included the letters a, c, e, m, n, o, r, s. All stimuli and alternatives were typed in lowercase letters on $6 \times 9$ in. white cards using an IBM Selectric typewriter and Courier typeface. The average length of the four-letter items was $.95 \mathrm{~cm}$, which, when viewed from S's station in an Iconix three-channel tachistoscope, subtended a visual angle of about $.6 \mathrm{deg}$.

Five experimental conditions were determined by the combination of specific letter alternatives and display type used on any trial. These conditions are illustrated in Table 1 . Words were presented in Conditions WW and WN, and the incorrect alternatives formed another stimulus word if exchanged with the correct alternative for WW trials, whereas this change produced nonwords for WN trials. Nonwords were presented in Conditons NW and NN, and, if exchanged for the correct letter, the incorrect alternative would have changed the display item to word or to another nonword stimulus, respectively. Thus, half the words and nonwords used differed from each other by only a single letter (Conditions WN and NW). The other stimuli formed pairs of words or nonwords that also differed by a single letter (Cond itions WW and NN). All nonwords were orthographically regular and pronounceable, and an attempt was made to match them with the words for the distributional and sequential redundancy of their component letters. Single letters were presented in Condition $\mathrm{L}$, and their locations varied over the same four positions occupied by the corresponding letters in the other conditions.

There were 128 different stimuli in each of the first four conditions shown in Table 1. The stimuli for each condition were divided into four groups of 32 items each for testing the four serial positions. The letter alternatives for each of these subgroups were visually similar for 16 items (both were from either Letter Group I or Letter Group II) and they were dissimilar for the other 16 (one alternative was used from each letter group). The constraints built into word and nonword displays limited the letter alternatives that could be tested at each serial position (ranging from nine different letters tested at Position 2 to all 14 alternatives tested at Position 3). The letters tested for the 32 trials for each position in Condition L were also subjected to the same constraints. Thus, the actual letters used as positive and negative alternatives were identical for each serial position across all five conditions.

All trials were divided into 16 blocks of 40 trials each. These 40 trials included two tests at each serial position for each of the five conditions, one using similar letters and one using dissimilar alternatives. The trial order within each block was randomized. The Ss were run for four 90-min sessions on separate days. Four trial blocks were presented on each day in a different random order to each S. On 2 days (odd days for half the Ss, even days for the others), the letter alternatives were presented before and after the display, and they were shown only after the display on the other 2 days.

Each day began with a set of 25 practice trials using stimuli similar to those used on experimental trials. The procedure for practice and experimental trials was the same. The trial began with a ready signal from $E$, after which $S$ pushed a footswitch to initiate the trial sequence. The first $500 \mathrm{msec}$ included a light field with a small, dark fixation point centered in the field if the alternatives were not shown before the display. In other sessions, the two letter alternatives appeared side by side, with two spaces between them in place of the fixation point. The correct alternative for any trial was randomly located to the left or right. At $500 \mathrm{msec}$ after $\mathrm{S}$ pushed the footswitch, the field went dark, and at $700 \mathrm{msec}$ the display was briefly exposed. The display appeared $.6 \mathrm{~cm}$ below the fixation point or letter alternatives. Exposure durations were individually adjusted to keep performance at about $75 \%$ correct responding, and mean durations for Ss varied from $1.4 \mathrm{msec}$ to $21.8 \mathrm{msec}$. After the display the field was again dark until the timer reached $950 \mathrm{msec}$, when the alternatives were displayed until $\mathrm{S}$ responded. The Ss indicated their responses by pressing a rightor left-hand button corresponding to the right or left letter alternative, respectively. They were instructed to respond on each trial even if unsure about which letter had been presented.

\section{RESULTS}

A 5 by 4 by 2 by 2 repeated-measures analysis of variance was performed on the mean proportion of correct responses for each $\mathrm{S}$ in each cell of the design. The factors corresponded to the five conditions, the four serial positions, whether or not the alternatives were 
presented before the display, and whether the letter alternatives were visually similar or dissimilar, respectively. Since all of these factors were within-S manipulations, a conservative $\mathrm{F}$ test was used following the recommendations of Box (1953). The analysis showed that the only significant effect was conditions, $F(1,7)=6.09, p<.05$. Mean proportions of correct responses for the five experimental conditions are presented in Table 1. Post hoc comparisions using a Scheffé test showed that Ss were more accurate for letter and word displays (Conditions $\mathrm{L}, \mathrm{WW}$, and WN) than they were for nonword displays (Conditions NN and NW).

\section{DISCUSSION}

The results demonstrated that Ss were more accurate in reporting which of two alternative letters was presented when the letters were presented alone or included in a common four-letter word than when included in an orthographically regular four-letter nonword. Thus, the advantage for words over single letters reported in similar perceptual recognition tasks (Reicher, 1969; Thompson \& Massaro, 1973; Wheeler, 1970) was not replicated. The most obvious differences between the previous experiments and the present study were the use of lowercase letters and the fact that the display was not followed by a masking field in the present study. Johnston and McClelland (1973) have also reported no accuracy difference between single letters and words in a similar experiment when the postexposure field was light and free of contours. Only when a pattern mask was used following the display did performance show an advantage for words. Effective masking is apparently more detrimental for perception of letters than for perception of words. The interaction of masking effects by type of display material was also observed by Bjork and Estes (1973). Thus, equivalent performance in Conditions WW, WN, and $\mathrm{L}$ in the present study need not imply that the same processes underlie letter identification when letters are presented alone or in meaningful words. Masking effects specific to letters or words indicate that different feature abstraction or subsequent encoding processes operate in the two cases. Redundant information available in words might be used to counteract the effects of lateral inhibition among the letters to produce no overall performance difference between single letters and words in the present study.

The results also do not replicate those of Baron and Thurston (1973) who reported no advantage for words over pronounceable nonwords. No difference would be expected if nonwords contain all the information available in words relevant for letter identification; namely, the visual features of letters and letter clusters conforming to the orthographic rules of English. If word identification is mediated by smaller visual or phonological units, no perceptual advantage should be obtained for words over regular, pronounceable nonwords. However, the results of the present study and of a series of studies reported by Manelis (1974) demonstrated the perceptual superiority of words over carefully matched nonwords in recognition tasks. The contradictory findings might be accounted for by the nature of the stimuli used in different experiments. Most of word stimuli used by Baron and Thurston (1973) were uncommon, low-frequency words. In addition, the total number of stimuli
Table 1

Mean Proportions of Correct Responses and Examples of the Test Stimuli and Choice Alternatives for the Five Experimental Conditions

\begin{tabular}{cccc}
\hline $\begin{array}{c}\text { Condi- } \\
\text { tion }\end{array}$ & $\begin{array}{c}\text { Alter- } \\
\text { natives }\end{array}$ & Display & $\begin{array}{c}\text { Propor- } \\
\text { tion } \\
\text { Correct }\end{array}$ \\
\hline WW & b r & bank & .729 \\
WN & b r & been & .740 \\
NW & b r & bose & .664 \\
NN & b r & bist & .678 \\
L & b r & b & .749 \\
\hline
\end{tabular}

was relatively small, and thus Ss were tested with the same stimuli repeatedly. The word stimuli in Manelis (1974) and in the present study, on the other hand, made up large samples of common words. The present findings support the argument that words are more perceptible because they are represented as units in an internal lexicon, whereas nonwords have no unitary internal representation. This higher-level unit information available in words is an additional source of redundancy that does not exist for orthographically regular and pronounceable nonwords.

\section{REFERENCES}

Baron, J., \& Thurston, I. An analysis of the word-superiority effect. Cognitive Psychology, 1973, 4, 207-228.

Box, G. E. P. Non-normality and tests on variances. Biometrika $1953,40,318-335$

Bjork, E. L., \& Estes, W. K. Letter identification in relation to linguistic context and masking conditions. Memory \& Cognition, 1973, 1, 217-223.

Estes, W. K., Bjork, E. L., \& Skaar, E. Detection of single letters and letters in words with changing vs unchanging mask characters. Bulletin of the Psychonomic Society, 1974, 3, 201-203.

Gibson, E. J., Shurcliff, A., \& Yonas, A. Utilization of spelling patterns by deaf and hearing subjects. In $H$. Levin and J. P. Williams (Eds.), Basic studies on reading. New York: Basic Books, 1970.

Johnston, J. C., \& McClelland, J. L. Visual factors in word perception. Perception \& Psychophysics, 1973, 14, 365-370.

Kucera, H., \& Francis, W. N. Computational analysis of present-day American English. Providence, R. I: Brown University Press. 1967

Manelis, L. The effect of meaningfulness in tachistoscopic word perception. Perception and Psychophysics, 1974, 16, 182-192.

Massaro, $D$. W. Perception of letters, words, and nonwords. Journal of Experimental Psychology, 1973, 100, 349-353.

Reicher, G. M. Perceptual recognition as a function of meaningfulness of stimulus material. Journal of Experimental Psychology, 1969, 81, 275-280.

Smith, E. E., \& Haviland, S. E. Why words are perceived more accurately than nonwords; Inference versus unitization. Journal of Experimental Psychology, 1972, 92, 59-64.

Smith, E. E., \& Spoehr, K. T. The perception of printed English: A theoretical perspective. In Kantowitz, B. H. (Ed.), Human information processing; Tutorials in performance and cognition. Potomac, M. D: Erlbaum Press, 1974.

Smith, F. Understanding reading. New York: Holt, Rinehart, \& Winston, 1971.

Thompson, M. C., and Massaro, D. W. Visual information and redundancy in reading. Journal of Experimental Psychology, 1973, 98, 49-54.

Wheeler, D. D. Processes in word recognition. Cognitive Psychology, 1970, 1, 59-85.

(R eceived for publication July 13, 1974.) 